\title{
Life cycle thinking in small and medium enterprises: the results of research on the implementation of life cycle tools in Polish SMEs_part 2: LCA related aspects
}

\author{
Joanna Witczak • Jedrzej Kasprzak • Zbigniew Klos • \\ Przemyslaw Kurczewski • Anna Lewandowska • \\ Robert Lewicki
}

Received: 12 August 2013 / Accepted: 10 December 2013 / Published online: 9 January 2014

(C) The Author(s) 2014. This article is published with open access at Springerlink.com

\begin{abstract}
Purpose This article is the second part of a series of articles presenting the results of research on the implementation of lifecycle management tools in small- and medium-sized companies in Poland. This work is part of a project financed by the Polish Agency for Enterprise Development (PAED), which began in February 2011. It was carried out by the Wielkopolska Quality Institute, a business environment institution associated with the Polish Centre for life cycle assessment (PCLCA). The main practical objective of the project was to support small and medium enterprises (SMEs) in their business development, e.g. by expanding their horizons beyond the sphere of their operation and identifying new areas for the improvement and promotion of the products and services they offer. The specific objective of the analysis on the environmental impact was an attempt to answer the question of whether environmental LCA is a good management tool for this type of business. Part 2 describes results of the evaluation of the implementation of LCA in SMEs conducted in 46 companies involved in the project.

Methods In order to assess the effectiveness of the project and the effectiveness of the implementation of LCA and life cycle costing (LCC), a survey was conducted of small and medium businesses where the implementation work had been fully completed. In total, 46 organisations agreed to participate in
\end{abstract}

Responsible editor: Gian Luca Baldo

J. Witczak $(\bowtie) \cdot$ A. Lewandowska $\cdot$ R. Lewicki

Faculty of Commodity Science, Poznan University of Economics,

Niepodleglosci 10, 61-875 Poznan, Poland

e-mail: joanna.witczak@ue.poznan.pl

J. Kasprzak $\cdot$ Z. Klos $\cdot$ P. Kurczewski

Faculty of Machines and Transport, Poznan University

of Technology, Piotrowo 3, 60-965 Poznan, Poland the LCA survey, which was almost $66 \%$ of all the companies where the LCA and LCC studies had been carried out within the project. The survey was conducted using individual indepth interviews. Questions to the representatives of the companies referred both to aspects of their functioning in the market (characteristics of a company, its market share, management systems, environmental policy, suppliers and clients) and the operation of their environmental service (assessment of its effectiveness, motivation and difficulties in its implementation), as well as opinions on the potential applications of LCA in their current operations.

Results and discussion The experience and observations of LCA experts resulting from their cooperation with the organisations analysed are largely supported by the results of the survey. The overall impression gained from the project is that the small- and medium-sized enterprises analysed have a problem with accepting and understanding the life cycle perspective and show limited interest in taking liability for environmental aspects beyond the mandatory legal standards and boundaries of their business operations. The survey shows that the companies rarely analyse environmental aspects appearing on many different stages of the life cycle of their products. Most of them focus on their current operations while trying to meet the mandatory legal requirements relating to environmental protection. It should be noted, however, that SMEs taking part in the studies appreciate the opportunities offered by LCA, their usefulness in business practice, recognise the potential for using life cycle techniques in the future and their impact on the management process, procedure or thinking about the products they manufacture. The result of the study is the identification of four key areas relevant to SMEs which may affect their willingness to adopt the life cycle perspective and undertake environmental measures.

Conclusions It seems that implementing LCT in small- and medium-sized enterprises requires a special approach. These 
are often companies with limited human resources (often just a few people) and financial resources (often operating on the verge of survival), with a weak position in a supply chain and, therefore, having various priorities in their daily operation. The researchers also encountered awareness barriers as a result of which the idea of going beyond an organisation and making an entire LCA of a product was often simply misunderstood. The studies conducted among SMEs have shown that managers' own intuition and research on customer preferences were largely conducive to improve existing or introducing new products or services, while changes were mostly introduced due to the requirements of the market, or the desire to reduce costs. It can be assumed that their non-obligatory nature also contributed to the relatively low interest in LCA initiatives and not recognising their usefulness. It seems that it would be useful to carry out relatively simple, but integrated, LCA/LCC analyses in SMEs so that the companies would clearly see the economic effect of the proposed environmental improvements. The analyses conducted lead to the conclusion that the incentive for SMEs to take measures should come from outside, e.g. as requirements for green public procurements, or as part of assessment made by suppliers in a supply chain.

Keywords Environmental aspects · implementation ·

LC perspective $\cdot$ SMEs

\section{Introduction}

In 2011-2013, life cycle assessment (LCA) analyses were carried out in 46 small and medium enterprises (SMEs) as part of a project financed by the Polish Agency for Enterprise Development, involving the implementation of LC techniques in small- and medium-sized enterprises (Kurczewski Part 1: Background and framework, Selech et al. Part 3: LCC related aspects). The main practical objective of the project was to support the companies in their business development, and one of the specific objectives was to raise awareness that environmental issues do not have to apply only to an organisation but they can also be analysed in other terms and lead to the improvement and promotion of products. Since the project involved a team of members of the Polish Centre for LCA (PCLCA) (Kulczycka et al. 2011), the reasons for its implementation went beyond purely business matters and also included methodological issues, and above all, they were intended to answer the question of whether Polish SMEs have the potential to implement LC techniques. Are Polish smalland medium-sized enterprises, often struggling with financial problems and the challenge of survival in the market, ready to accept Life Cycle Thinking and take responsibility for environmental issues beyond their own organisations? And finally, what could mobilise the organisations to take/continue LCA measures? It seems especially important if, taking into account that the use of LC techniques by SMEs is still marginal, there are only a few publications in this area (Baumann et al. 2012; Schischke et al. 2012; TNO 2005).

\section{Survey}

In order to answer these questions, a survey was conducted among the companies participating in the project (Kurczewski Part 1: Background and framework). The research was based on individual in-depth interviews (Boyce and Neale 2006), while respondents were representatives of top management or persons directly connected with the implementation of LCA in individual companies. Twenty-five companies, representing $54 \%$ of all organisations where the environmental service had been implemented, agreed to participate in the study of environmental LCA. A questionnaire for the environmental service assessment was divided into four sections:

- Section 1: the main goal of this part of the questionnaire was to obtain a picture of a company and its market position. Questions in Part 1 focused, on the one hand, on general issues, such as name, number of employees, organisational and legal structure and scope of business, while on the other hand, they referred to information on management systems and allocation of powers (in relation to major areas of business), the characteristics of suppliers (scope of business, size of the organisation and possibility of subsidy) and clients (institutional versus individual, scope and size of the institutions) and the business's market share. Some of the data were obtained earlier, at the stage of selecting firms for the project and at the first introductory meeting, so they were often placed in the questionnaire by an interviewer before an interview. The task of a company's representative was to verify and clarify them.

- Section 2: the second part of the questionnaire concerned environmental services implemented in a company and included issues related to the object and scope of the LCA, the positions of people who agreed to carry out the study and supervised its progress, the method of communication with a company, the procedure for collecting inventory data and motives for implementing the service. Here, some of the information was also known to persons responsible for providing the service in a company, it was entered in advance, before an interview.

- Section 3: this section contained questions designed to evaluate the effectiveness of the analyses from the point of view of the companies. Representatives of the organisations evaluated the usefulness of LCA results and determined their actual or possible applications. They also stated whether the LCA conducted changed their 
management models, conduct or thinking about their products. In addition, they identified issues that caused most problems in the implementation of the environmental service.

- Section 4: the last part of the questionnaire was designed to obtain information as to whether and to what extent the organisations analysed undertook activities related to environmental protection or environmental management. Preliminary information of this type was obtained from the companies prior to the classification of the companies for different areas of the project and at the first meeting when the purpose and scope of the LCA were jointly determined.

Part 1 of the series of articles contains a full description of the survey questionnaire (Kurczewski Part1: Background and framework).

\subsection{Survey sample}

In total, 25 firms out of 46 companies where an LCA had been carried out as part of the project responded to the survey. The group of organisations analysed included 12 manufacturing companies, 6 service providers, 5 service and manufacturing companies, and 2 trading firms. The average number of employees in the organisations studied was 29 people, and $44 \%$ of them were micro-enterprises with fewer than 10 employees (11 companies), $48 \%$ of all entities were small businesses employing up to 50 people (12 companies) and 2 organisations that met the criteria of medium-sized firms (employing between 50 and 250 people) (Table 1). The majority of the organisations (18 firms) were private, self-employment businesses, while the others were two private partnerships, two registered partnerships and three limited liability companies (Table 1). Taking into account the results of the study, it should be stressed that self-employment in Poland is the simplest form of conducting business, characteristic mainly of small enterprises. It is run under one's own name and for one's own account, while an owner is liable with all their assets. This may be important for the analysis of the research results, particularly when it comes to the tendency of companies to take risks and engage in environmental projects beyond the scope of organisations.

Another point to be considered when describing the situation in the companies analysed involved management methods. There were questions about the types of management systems in companies. As indicated by the information presented in Table 1, 14 of 25 organisations (56\%) had no formal management systems. The quality management system according to ISO 9001 was implemented in nine of the companies analysed and took second place. Only four organisations had more than one management system.
Table 1 Characteristics of the companies participating in the survey where LCA was implemented - by size, legal and organisational structure and management systems

1. Size of the companies analysed

$\begin{array}{lll}\text { Micro } & 11 & 44 \% \\ \text { Small } & 12 & 48 \% \\ \text { Medium } & 2 & 8 \% \\ \text { Total } & 25 & 100 \%\end{array}$

2. Legal and organisational structure of the companies analysed

Self employed $\quad 18 \quad 72 \%$

Private partnership $\quad 2 \quad 8 \%$

Registered partnership $\quad 2 \quad 8 \%$

Limited liability company $\quad 3 \quad 12 \%$

Total $\quad 25 \quad 100 \%$

3. Management systems in the companies analysed

3.1 According to the number of systems implemented

$\begin{array}{rll}\text { No systems implemented } & 14 & 56 \% \\ 1 \text { System implemented } & 7 & 28 \% \\ 2 \text { Systems implemented } & 3 & 12 \% \\ \text { 3 Systems implemented } & 1 & 4 \% \\ \text { Total } & 25 & 100 \%\end{array}$

3.2 According to the type of system implemented

ISO 14001

EMAS

Cleaner Production

$7 \%$

$0 \quad 0 \%$

Responsible Care

ISO 9001

BHP OHSAS 18001

HACCP

ISO 22000

ISO 27001

Others

No formalised management systems

Total

$0 \quad 0 \%$

$0 \quad 0 \%$

$9 \quad 30 \%$

$9-30 \%$

$13 \%$

$13 \%$

$0 \quad 0 \%$

$0 \quad 0 \%$

$3 \quad 10 \%$

$14 \quad 47 \%$

$30 \quad 100 \%$

From the point of view of management processes, delegation of tasks and work organisation in key areas is also important. For this reason, owners of the companies were asked about their ways of conducting their activity in the areas of environmental protection and environmental management, design/research and development, quality management, payroll planning and calculation, employee cost analysis, finance and control and product cost analysis (Fig. 1).

The first general observation of the results presented in Fig. 1, where black and 'marble' are the predominant colours, indicates a clear advantage of individual activities within these five areas. An exception may be the area of design and R\&D, as here, 7 out of 25 organisations studied did not show any activity, which may be due to their specific nature, as all of these companies are service and trading entities that, 'by definition', find this type of activity of little significance. 
Fig. 1 Ways the companies analysed conducted activity in five selected areas
How do you conduct activity in the selected areas

[as number of the companies analised with a positive answer]

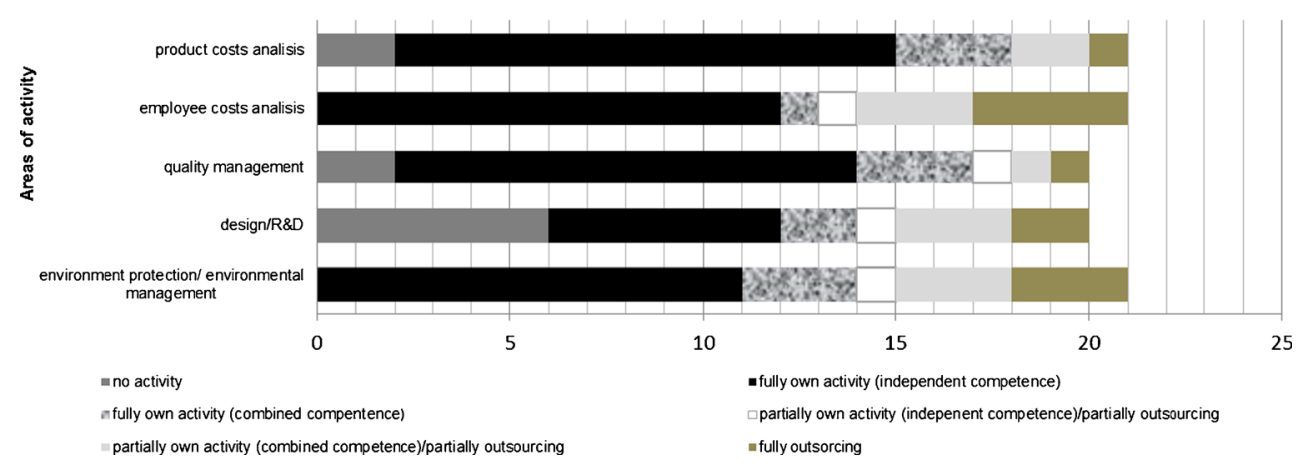

At this stage of the survey, representatives of 22 of the companies declared their engagement in any activity in the field of environmental protection and environmental management, while, as shown in Fig. 1, in most cases, they claimed to pursue such activities on their own. Twelve organisations established an independent job position/department for this purpose [black in Fig. 1-full own activity (independent competence)], and in three other organisations, they were implemented by persons with combined competence [marble colour in Fig. 1-full own activity (combined competence)]. A minority of the organisations analysed claimed to outsource the implementation of measures in the areas of environmental protection/environmental management (three companies); the remaining four shared it between their own activities and outsourcing.

From the point of view of SME potential, the position of a company in the market and a supply chain is also important. For this reason, interviewers asked about the type, size, range and position of suppliers (suppliers of the main and auxiliary resources and products) and clients (individual and institutional) of the organisations analysed. The results related to suppliers are presented in Fig. 2. Suppliers of the main resources and products were dominated by medium-sized and large domestic and foreign companies. There were slightly over $30 \%$ of local suppliers, particularly small- and mediumsized organisations. The situation was different with regard to suppliers of auxiliary products. In this case, almost half of them were small- and medium-sized local suppliers, then bigger domestic suppliers, while the share of foreign suppliers was identified as marginal. With regard to suppliers of the main resources and products, the companies analysed most often determined their position as 'secondary', and as for the second category of suppliers, the prevailing relationship was 'equal'.

Organisations that decided to take part in the survey primarily had institutional clients (62\%), mainly local and domestic (Fig. 3). There was no significant correlation between the type of clients and business activity. Both manufacturing and service entities had institutional clients (such as a laundry service, or a metal or glass processing service).
2.2 LCA studies in the companies analysed: general information

An LCA of products was carried out in 19, and an LCA of services in 6 out of the 25 companies analysed. In 16 cases, it was a cradle to grave analysis, in six cases, from cradle to gate analysis, and in three cases, from gate to gate analysis. In all of the cases, the decision to conduct an LCA was made by management, mainly by owners but in the case of two limited liability companies by the presidents of the boards. Interestingly, in most cases, owners were also directly supervising the conduct of the study and were responsible for contacts with LCA experts. Quality managers were responsible for these activities in five companies where quality management systems according to ISO 9001 had been implemented.

Another topic of interest in the implementation of LCAs in SMEs concerned problems associated with the collection of inventory data. In each case, cooperation began at the first introductory meeting, attended by representatives of a company's management and LCA experts. The purpose of including the latter was to present the ideas and principles of an LCA and determine, together with the representatives of the companies, the main objectives of the LCA study. They discussed the subject of the analysis and sought to define a specific area of the analysis that would be of practical application in a particular company. In many cases, the boundaries of a product system and the division of the system into unit processes were already pre-determined at the first meeting, and a qualitative assignment of inputs and outputs for each of them was made. On this basis, LCA experts prepared forms to collect inventory data. Three companies out of all the participants in the survey had taken upon themselves the task of collecting data. Based on the form, they gathered all the necessary information, without direct involvement of LCA experts. In all other cases, the organisations required greater or lesser support in collecting inventory data. This support consisted mainly of individual personal visits of LCA experts to the companies, as well as telephone and e-mail contacts. Of the 25 organisations, five passed over the entire task of 
Fig. 2 Suppliers of the companies analysed - according to their size and geographical scope
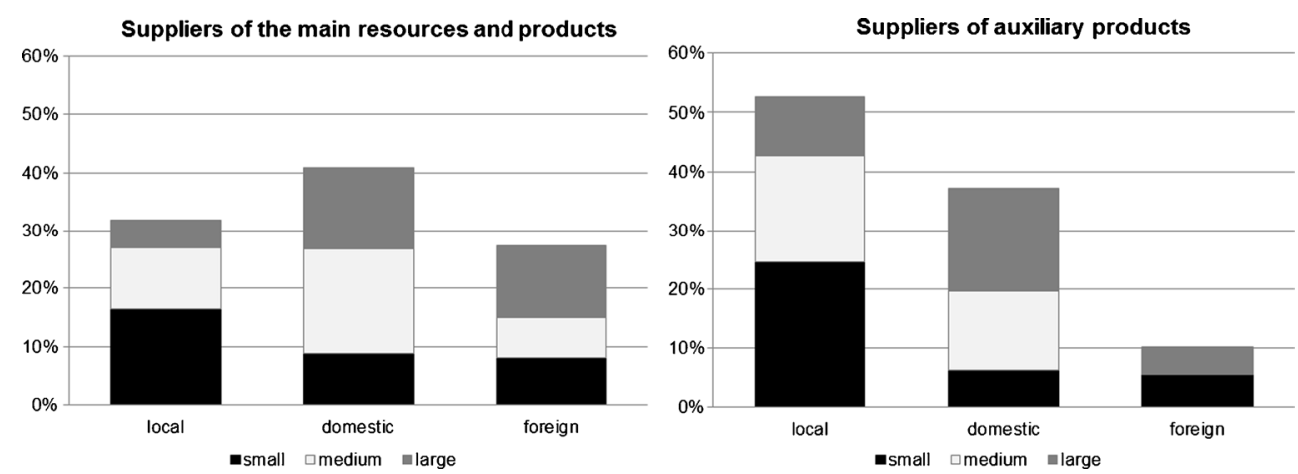

collecting data into the hands of the LCA experts. In this case, the latter spent much more time on the premises of the companies, because they had to reach relevant persons and documents. The quality of inventory data differentiated between LCA case studies and depended rather more on the companies' willingness to cooperate than on the type of persons engaged in data collecting (employees versus external LCA experts).

In assessing the potential role of SMEs in life cycle management, it is important to know the reasons why these companies are willing to carry out LC analyses. The results of such an assessment in relation to the organisations analysed are presented in Table 2 in which one column lists 12 motives and the other an average rating assigned by the companies analysed $(0=$ insignificant, $5=$ very significant $)$. As can be seen, the highest scores were obtained for three reasons:

- $\quad$ product improvement plans_-result: 4.4

- opportunity to show a certificate confirming participation in the project and the cooperation with the centre supporting entrepreneurship, which is well-known in the region-result: 4.2

- free service-result: 4.0 .

Generally, three groups can be identified among the companies analysed based on the answers to this question. The first may include those that gave the highest score to product improvement plans or new product development, while

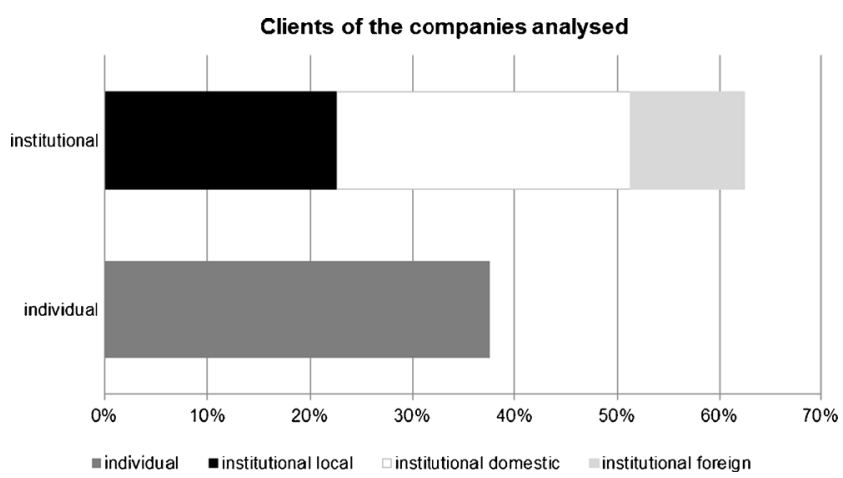

Fig. 3 Clients of the companies analysed-according to type and geographical scope significantly lower was assigned to the other arguments, including the opportunity to show a certificate or free service. There were six such companies out of 25 , that is, $24 \%$ of the total. The second group included seven organisations that gave greater weight to the arguments of free service and certification rather than product improvement or new product development. The third group may include organisations (12 companies) that found all these three reasons equally important. Other arguments had evidently much smaller impact on the decision to carry out an LCA, while the lowestrated categories were competition $(0.8)$, requirements of suppliers (0.8), client preferences (1.2) and perception of products as hostile to the environment (1.5).

The final issue raised in the second part of the interview was an LCA report. Each company was provided with an LCA report which included the following chapters: methodological overview of the LCA technique, reasons for the selection of the product or service to be studied and its characteristics, goal and scope (function, functional unit, reference

Table 2 Reasons for participation in the project and LCA

\begin{tabular}{|c|c|c|}
\hline \multicolumn{2}{|c|}{ Motivation for LCA } & \multirow{2}{*}{$\begin{array}{l}\text { Compliance by a 5-point } \\
\text { scale (as a weighted average) } \\
0=\text { insignificant }(\min ) \\
5=\text { very significant }(\max )\end{array}$} \\
\hline 1 & New product development & \\
\hline 2 & Product improvement plans & 4.4 \\
\hline 3 & Free service & 4.0 \\
\hline 4 & $\begin{array}{l}\text { Cooperation with the well-known } \\
\text { Centre (getting a certificate } \\
\text { confirming the cooperation) }\end{array}$ & 4.2 \\
\hline 5 & $\begin{array}{l}\text { Existing product/process seen as adversely } \\
\text { affecting the environment }\end{array}$ & 1.5 \\
\hline 6 & Similar measures taken by competition & 0.8 \\
\hline 7 & Creating an image in the eyes of suppliers & 2.8 \\
\hline 8 & Creating an image in the eyes of clients & 4.0 \\
\hline 9 & At the express request of suppliers & 0.8 \\
\hline 10 & $\begin{array}{l}\text { At the express request of clients } \\
\text { (their reported preferences) }\end{array}$ & 1.2 \\
\hline 11 & Applying for an eco-label & 2.0 \\
\hline 12 & $\begin{array}{l}\text { Development/implementation of } \\
\text { environmental management system }\end{array}$ & 2.4 \\
\hline
\end{tabular}


flows and life cycle stages included in the analysis), life cycle inventory (assumptions and LCI results), reasons for the selection of the LCIA method (with an explanation of the essential features of the method and results obtained with it), LCIA results and recommendations for further improvement of the study target. In each case, the report was presented to management and/or analysed by the owners. The information contained in the reports was considered understandable (weighted mean score for intelligibility $=4.2$ ), although moderately simple (weighted mean score for intelligibility $=3.3$ ).

\section{Usefulness of LCA to the companies analysed}

The results of the interviews show that the companies evaluated the usefulness of the results presented in the report on the implementation of environmental services (LCA) that was submitted as fairly good (mean score 4.4) (Fig. 4).

The assessment of their potential practical usefulness takes similar form. Most companies ( $76 \%$ ) found that practical use of the LCA results may prove possible in the future. The potential areas of application of LCA results are presented in Table 3.

In the opinion of the companies participating in the study, the results would be the most useful in creating an environmentally friendly image of an organisation or product (score 4.6 and 4.7) and for generally understood marketing objectives (score 4.1). Their application in product development (score 3.9) or packaging improvement (score 2.4) was perceived as of a little less value. The results indicate that most of the firms in the study see the possibility and usefulness of applying the LCA results in marketing. It should be noted that creating an image in the eyes of clients received a very high score in the assessment of reasons for participation in the project and in the analysis presented by the companies surveyed (Table 2).

Following this, the representatives of the organisations analysed were asked about possible difficulties encountered

Evaluation of the usefulness of the LCA analyses

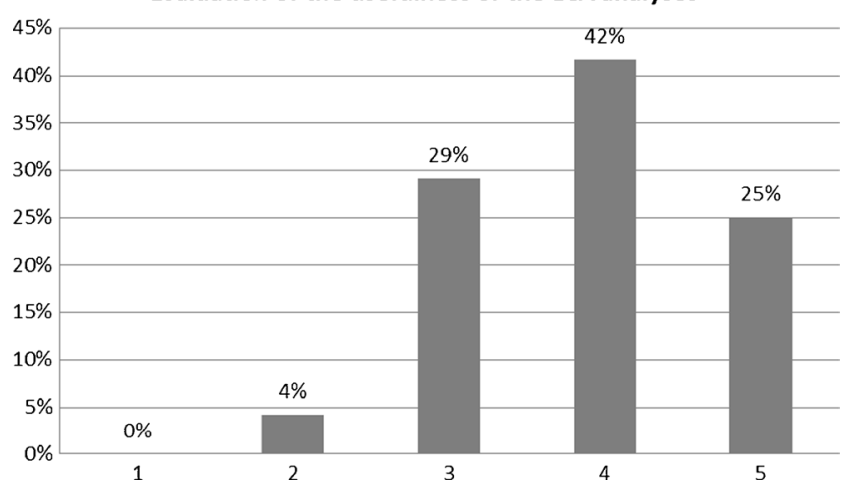

Fig. 4 Evaluation of the usefulness of the LCA analyses, where $0=$ insignificant $(\mathrm{min})$ and $5=$ very significant $(\max )$

Table 3 Potential areas of application of LCA results according to the companies analysed

Areas of application of

LCA results
Compliance by a 5 -point scale (as a weighted average) $0=$ insignificant $(\mathrm{min})$ $5=$ very significant $(\max )$

$\begin{array}{lll}1 & \text { Marketing } & 4.1 \\ 2 & \text { Product development } & 3.9 \\ 3 & \text { Packaging improvement } & 2.4 \\ 4 & \text { Creating an image of a product } & 4.7 \\ 5 & \text { Creating an image of an organisation } & 4.6 \\ 6 & \text { Educational activities } & 0.1\end{array}$

during the implementation of an LCA. Collecting data was a frequently cited problem ( $32 \%$ of responses), but most people pointed to the lack of any difficulties ( $40 \%$ of responses) (Fig. 5). It should be noted, however, that only three companies (12\% of respondents) among all participants in the survey took over the entire task of collecting data, and they gathered all the necessary information on the basis of the form that they obtained. In other cases, direct involvement of LCA experts was necessary. The results show that far fewer problems were caused by the analysis of the report and data contained therein (16\% of responses), as well as the implementation of results and recommendations (12\% of responses). This could, however, result from the fact that the report was provided individually, along with a brief commentary for the companies involved in the project.

A particularly positive feature is the fact that the individuals surveyed declared that LCA results had already changed, or might change in the future, their management models, business thinking and development of products or services. Almost $64 \%$ of the enterprises analysed could foresee such a possibility (Fig. 6).

Getting companies acquainted with the capabilities offered by an LCA also influenced their perception of the prospects of using life cycle techniques in the future. The opinions of the companies are presented in Fig. 7.

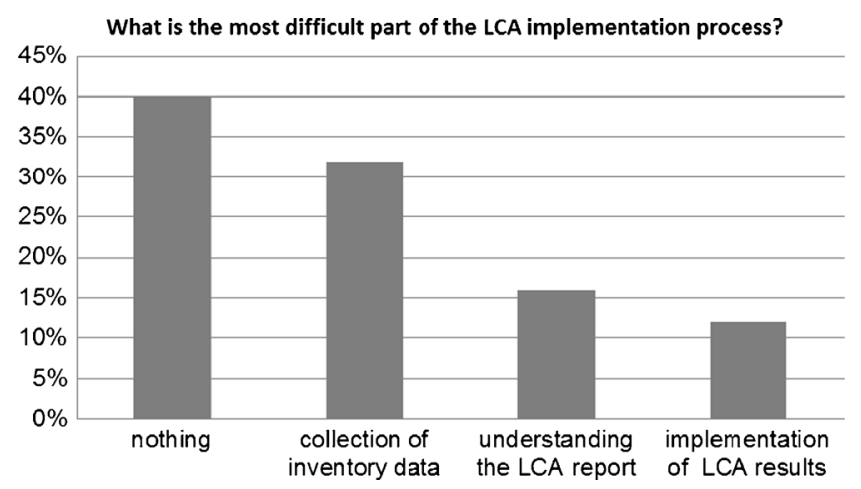

Fig. 5 Respondents' answers to the question. 'What is the most difficult part of the LCA implementation process?' 


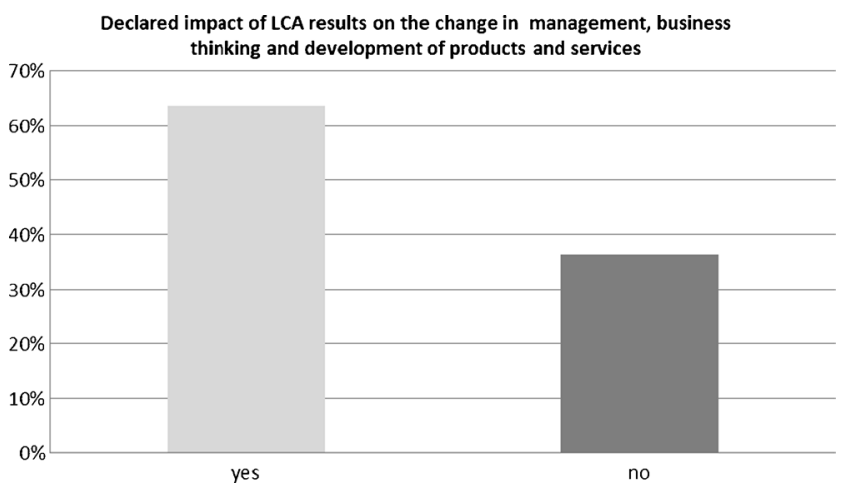

Fig. 6 Declared impact of LCA results on the change in management, business thinking and development of products/services in the companies analysed

A specific confirmation of the usefulness of LCA is that almost all the companies participating in the survey saw possibilities for using life cycle techniques in their future activities. Most (91.7\%) of the companies analysed believed that such opportunities existed, and $20.8 \%$ declared they would definitely opt for their use. This demonstrates that the advantages of an LCA and the possibility of its practical application in business have been noticed.

\section{Life cycle thinking and companies' environmental activity}

The purpose of the fourth part of the interview was to obtain more detailed information about the ways environmental activities were implemented in the organisations surveyed. The first question concerned the environmental analyses performed. Taking into account the responses received in the initial part of the survey, in which all of the organisations analysed declared having undertaken some environmental activity, mainly positive responses were expected. Surprisingly, only $52 \%$ of the organisations indicated that they had carried out any environmental analyses as part of their environmental activities. It should be noted that the interviews were conducted with relevant persons holding the

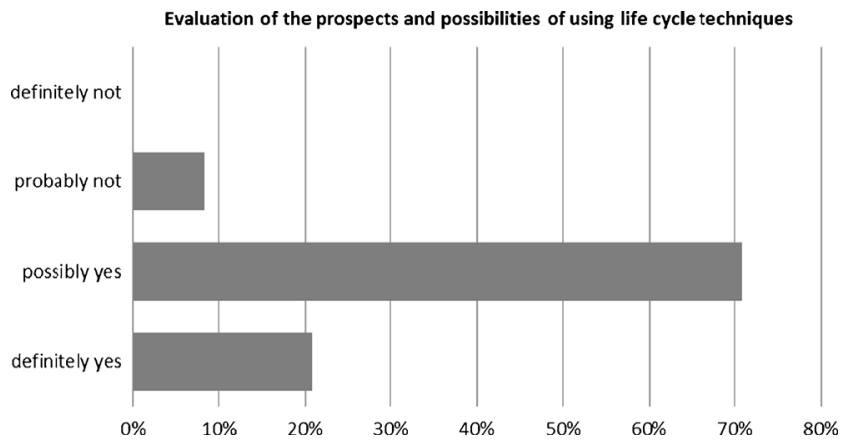

Fig. 7 Evaluation of the prospects for and possibilities of the companies using life cycle techniques in the future most important or important functions in the organisations analysed. Therefore, theoretically, it is unlikely that the respondents did not know about such activity if it had actually been implemented by the companies. The fact is that in Part 4 of the survey, only 13 of the 25 organisations responded positively to the question. 'Does the company take any measures in the area of environmental protection, environmental management or implement any environmental policy?' In most cases, representatives of the 13 organisations claimed to make reports on environmental fees, compulsory in Poland under the Environmental Protection Act (2001), Water Act (2001), Waste Act (2001) and the Regulation of the Council of Ministers on environmental fees dated 14 October (2008). It is worth noting that all entrepreneurs in Poland who have cars, trucks, company agricultural machinery introducing gases or dust into the air as a result of technological processes, draw water from their own intakes, bring sewage to water or soil and stockpile waste are obliged to pay such fees (Environmental Protection Act 2001; Water Act 2001; Waste Act 2001; Regulation of the Council of Ministers on environmental fees dated 14 October 2008).

In the following part of the interview, questions were asked to verify whether the entrepreneurs analysed took any ecological measures other than the environmental analyses. Seven areas related to environmental impact that might be subject to potential assessment by the companies were taken into account. These included the environmental performance of suppliers, environmental issues in internal and external transport, environmental issues in media and energy consumption, environmental issues in product design, environmental issues in product packaging and the end of life of products. Figure 8 shows to what extent they were applied in the on-going activities of the respondents. The positive aspect seems to be that two of the areas analysed which received the highest scores, environmental issues in product design and product packaging, are those that manifest ecologically friendly thinking in the area of product development and prove that environmental aspects are integrated into the conceptual stages.

In terms of the environmental performance of suppliers, the activity of the organisations analysed came down largely to the acquisition of certified materials (but it was not specified whether it referred to safety approvals or strictly to environmental certificates) and the verification of the certificates of the environmental management systems possessed by suppliers. In terms of internal and external transport, the use of electric forklift trucks and cars that met the latest emission standards was identified as a manifestation of their environmental performance. In the case of media consumption, the purchase of energy-efficient heating devices and technological machines was indicated. The organisations analysed paid the least attention to the end of life of their products. Five organisations that gave a positive answer to this question indicated 
Fig. 8 Environmentally friendly measures, other than environmental analyses, carried out by the organisations analysed (*excluding one company for which it was not applicable; **excluding two companies for which it was not applicable and one company that did not reply to the question)

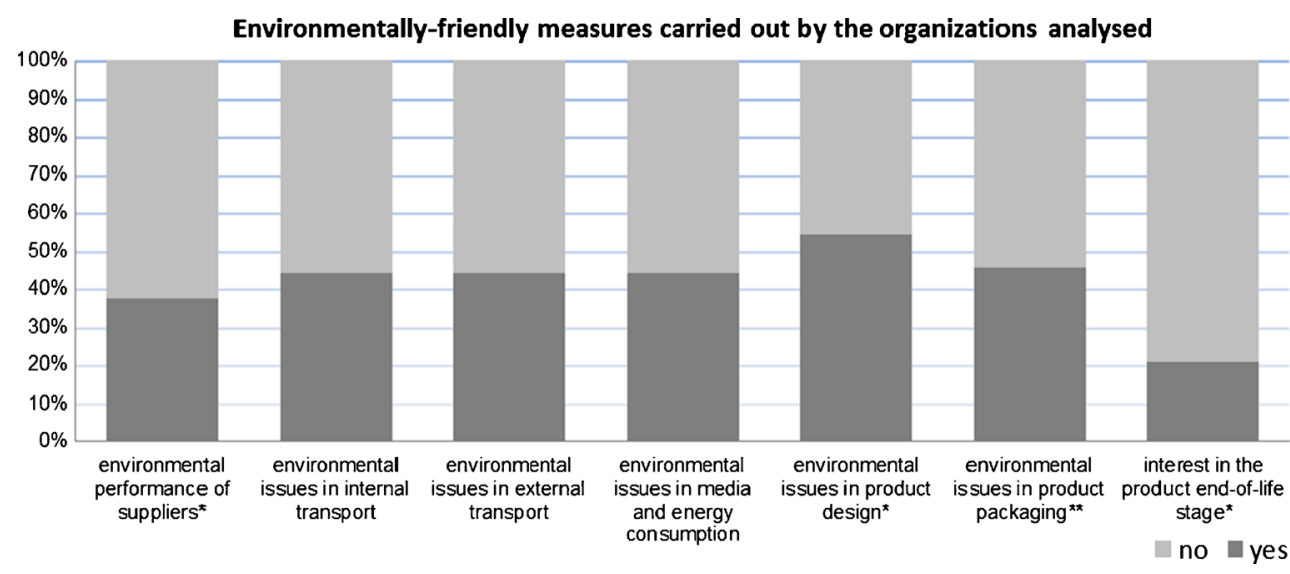

the following measures: teaching users how to extend the life of products, organising waste management and using certificates known as 'life cards'.

To assess the development and innovation potential of SMEs, it is important to know the reasons for decisions to improve existing products or services or introduce new ones. The results of such an assessment in relation to the organisations analysed are presented in Table 4 in which the first column lists six reasons for making decisions and the second column presents an average rating issued by the company analysed $(0=$ insignificant, $5=$ very significant $)$. As the following results show, the companies attached the greatest importance to their own intuition and creativity (4.4), analysis of client preferences (3.7) and analysis of patents and technological innovations (2.9).

Tables 5 and 6 present the evaluation of criteria affecting decisions to change existing products and reasons for carrying out an LCA in the future. Decisions on product changes in the companies analysed are influenced by the desire to meet the needs of the market and image creation (4.0 each), the desire to gain a competitive edge (leadership 3.8) and the desire to comply with legal requirements and reduce costs (3.8 each).

As the studies show, the reasons most frequently indicated by respondents for carrying out an LCA were mandatory legal

Table 4 Reasons for decisions to improve existing products or services or introduce new ones in the companies analysed

\begin{tabular}{|c|c|c|}
\hline \multicolumn{2}{|c|}{$\begin{array}{l}\text { Reasons for decisions to improve } \\
\text { existing products or services or } \\
\text { introduce new ones }\end{array}$} & \multirow{2}{*}{$\begin{array}{l}\text { Compliance by a 5-point scale } \\
\text { (as a weighted average) } \\
0=\text { insignificant (min) } \\
5=\text { very significant (max) } \\
2.0\end{array}$} \\
\hline 1 & Imitating competition & \\
\hline 2 & Analysis of client preferences & 3.7 \\
\hline 3 & Own intuition and creativity & 4.4 \\
\hline 4 & $\begin{array}{l}\text { Analysis of patents and } \\
\text { technological innovations }\end{array}$ & 2.9 \\
\hline 5 & Own patents and developments & 0.2 \\
\hline 6 & Applicable standards & 0.2 \\
\hline
\end{tabular}

requirements (4.6), creating the image of an organisation (3.9) and strong environmental trends (3.8). The first of these is indisputable, while the other two once again confirm the marketing usefulness of an LCA which was recognised by the companies participating in the study. These statements are also consistent with the most frequently mentioned criteria affecting decisions on changes in the existing products in the companies analysed, i.e. the desire to meet the needs of the market, which is the primary marketing goal of enterprises and image creation (4.0 each).

\section{Discussion and conclusions concerning LCA related aspects}

Chapters 2-4 describe the organisations surveyed and present the results of interviews with their representatives. In chapter 5 , the results are discussed and compared with the observations of LCA experts, made over several months of cooperation with all 46 firms which had implemented an LCA (not just those who decided to take part in the survey).

Table 5 Criteria affecting decisions to change existing products in the companies analysed

Criteria affecting decisions to change existing products
Compliance by a 5-point scale (as a weighted average) $0=$ insignificant $(\mathrm{min})$ $5=$ very significant $(\max )$

1 Cost reduction $\quad 3.8$

2 Competitive advantage (leadership) $\quad 3.8$

3 Catching up with the competition 2.8

4 Compliance with legal requirements $\quad 3.8$

5 Meeting the needs of the market $\quad 4.0$

6 Measures enforced by business partners 2.0

7 Image creation 4.0

With the exception of one of the companies where the question does not apply 
Table 6 Main motives for carrying out an LCA in the future

\begin{tabular}{|c|c|c|}
\hline \multicolumn{2}{|c|}{$\begin{array}{l}\text { Motivation for carrying out } \\
\text { an LCA in the future }\end{array}$} & \multirow{2}{*}{$\begin{array}{l}\text { Compliance by a } 5 \text {-point } \\
\text { scale (as a weighted average) } \\
0=\text { insignificant (min) } \\
5=\text { very significant (max) } \\
4.6\end{array}$} \\
\hline 1 & $\begin{array}{l}\text { Legal requirements (if this type of } \\
\text { analysis becomes obligatory) }\end{array}$ & \\
\hline 2 & Strong environmental trends & 3.8 \\
\hline 3 & $\begin{array}{l}\text { Similar analyses performed by the } \\
\text { competition }\end{array}$ & 2.4 \\
\hline 4 & LCA suggested by key suppliers & 2.9 \\
\hline 5 & $\begin{array}{l}\text { Compliance with environmental } \\
\text { criteria in public procurement } \\
\text { (acting as a contractor in tenders) }\end{array}$ & 3.2 \\
\hline 6 & Creating an image of an organisation & 3.9 \\
\hline
\end{tabular}

Lack of response from one of the companies

It seems that there are five key areas primarily responsible for determining the specific features of SMEs, and which may affect the willingness to adopt a life cycle perspective and implement environmental policy:

- company management and division of powers: 'holding power in one hand' was a characteristic of most of the participating companies as private entities with a low level of employment. Decisions related to conceptual activities (design and development), costs of products (including pricing, margins), promotion and marketing, and quality management issues (mainly analysing the causes of returns and complaints) were often made by an owner. On the one hand, it can be seen as an advantage, because one, undispersed 'source' of decisions should theoretically speed up decision-making processes. What is more, owners knew their businesses 'from the inside', which meant that they were complex, but unfortunately often the only competent source of information in the entire organisation. In addition, as a result of one-man management, owners tend to be saddled with a number of different responsibilities and focus only on areas they consider crucial for the functioning of their organisations. If they analyse trends and competition, they focus rather on nonenvironmental aspects. Owners frequently did not have time to collect and evaluate data collected during the project. In many cases, despite the preliminary enthusiastic attitude to the idea of an LCA, the willingness to cooperate declined after the guidelines on the scope and type of inventory data required were learned. They often obtained selective data that did not allow the balancing of unit processes. Some organisations where an LCA had been conducted expected quick results based on a small amount of data. Commonly, there was a conviction that the analysis would be based on information similar to that required for mandatory environmental reports submitted by companies to marshal's offices, and which would refer only to their operation. Therefore, it proved problematic to obtain data related to suppliers, handling a product during use and organising waste treatment. Collaboration with those companies where persons were specifically delegated to collect contacts and data was clearly more effective, mentality: the situation in the SME market is often more fragile than that of large organisations; hence, they are characterised by short-term thinking, 'here and now', which is not conducive to the implementation of a life cycle perspective. Representatives of the companies analysed were often genuinely surprised by the proposal to take the analysis beyond the boundaries of their organisations and focus on indirect environmental aspects. Most companies limited their environmental activities to make mandatory reports. The overall impression is that environmental issues are generally seen from the angle of compulsory laws and rarely associated with voluntary development activities. Perhaps to some extent, this can be explained by the fact that only two organisations had an environmental management system according to ISO 14001. The way of thinking of the organisations analysed may also be determined by the fact that they pointed to the cost-free nature of the analysis and the opportunity to gain certification as the main reasons for making an LCA, factors which were often more important than product development and image building,

- resources: limited resources, especially human resources, seem to be a significant barrier to the implementation of life cycle techniques in SMEs. In the case of micro- and small-sized enterprises with low employment status, personnel training and systematic analyses are problematic. From this point of view, carrying out such analyses from time to time and outsourcing them to an independent body are more likely to occur than a situation in which the use of LC techniques becomes an inherent part of the daily management of an organisation and its products,

- position in a supply chain: for the majority of companies participating in the project, suppliers of the main resources and products were medium and large domestic and foreign enterprises. The companies described their relationships with those suppliers as of secondary importance, indicating their rather weak position in the supply chain. The analysis of reasons for carrying out an LCA showed that the incentive did not come from suppliers. The desire to create an image in the eyes of suppliers, however, obtained a higher score but still oscillated around a moderate rating. The impact of clients on the decision was also low. In this case, it is quite irrelevant that they were mostly institutional clients. It can be assumed that environmental awareness in Poland is quite low, which is reflected in the approach of both retail and institutional clients. Nevertheless, the companies recognised the possibility of using LCA results in marketing and creating an image in the eyes of clients, 
- flexibility: the limited size of the small and medium companies - where a few, a dozen or rarely a few dozen people are usually employed - gives the owners/managers the possibility of exerting a direct impact on their workers. If the owners decide to carry out a pro-environmental activity in their companies, their decision has a chance of being quickly and directly communicated to and approved by all employees. On the other hand, the SMEs have a tendency to form alliances in order to achieve a particular goal, for instance, to increase their competitiveness.

Life cycle assessment has been present in Poland for several years, but so far, its application in Polish industry has been generally limited to large companies, for example, from the metal sector (Bieda 2012a, 2012b). In view of the results of the survey, the question arises whether an environmental LCA is a good tool for small- and medium-sized enterprises? LCA, as part of environmental management, is voluntary and is a manifestation of a 'higher' and more forward thinking management (Baumann 2000). The analysis should not be made simply for the sake of analysis and an opportunity to show a certificate or note this fact in the official documents of a company. It seems that among the SMEs analysed, the risk of such 'formalism' was high, which could distort the actual usefulness of this tool. It would be most valuable to 'build' a life cycle perspective into an enterprise and introduce it into decision-making processes. When will this become possible? When will an LCA become a mandatory analysis through regulation? The example of the enterprises studied makes this scenario doubtful. The motivation should rather 'come' from the outside but as a result of market forces and allowing organisations to take such initiatives on their own accord. Our experience shows that cooperation with companies that independently ask a contractor to carry out an LCA study for them is quite different. A chance may be seen in the green public procurement process. In view of a number of barriers to small- and medium-sized enterprises in the public procurement market (DG Enterprise and Industry 2010), the greening of procurements is seen as an opportunity for SMEs to gain additional advantages.

Finally, the key question returns 'are Polish small- and medium-sized enterprises ready to accept Life Cycle Thinking and take responsibility for environmental issues beyond their own organisations?' The experience of LCA implementation in 46 small and medium size Polish enterprises gives reasons to be moderately optimistic. The situation seems to be not perfect but a potential exists. The interviews show that the companies gave a fairly good evaluation to the usefulness of LCA results, and almost all the companies participating in the survey saw possibilities for using LCA in their future activities. An intensive information campaign and
LCA courses, changing generations in environmental managers' posts and an increase in the popularity of green jobs (as a challenge for the higher educational system in Poland) would facilitate the process of implementing LCT in Polish SMEs.

Open AccessThis article is distributed under the terms of the Creative Commons Attribution License which permits any use, distribution, and reproduction in any medium, provided the original author(s) and the source are credited.

\section{References}

Baumann H (2000) Introduction and organisation of LCA activities in industry. Description and analysis of two LCA projects in Swedish Companies Int J Life Cycle Assess 5(6):363-368

Baumann M, Held M, Herrmann C, Saraev A, Riese O, Steininger H (2012) Ecodesign tool for SMEs in the electronics sector IN: Electronics Goes Green 2012+, Proceedings of the Joint International Conference and Exhibition September 9 - 12, 2012 Berlin, Germany, pp 1-8

Bieda B (2012a) Life cycle inventory processes of the ArcelorMittal Poland (AMP) S.A. in Kraków. Poland basic oxygen furnace steel production. Int J Life Cycle Assess 17:463-470

Bieda B (2012b) Life cycle inventory processes of the Mittal Steel Poland (MSP) S.A. in Krakow, Poland -blast furnace pig iron productiona case study. Int J Life Cycle Assess 17:787-794

Boyce M, Neale P (2006) Conducting In-Depth Interviews: A Guide for Designing and Conducting In-Depth Interviews for Evaluation Input. Pathfinder International Tools Series; Monitoring and evaluation-2. http://www.cpc.unc.edu/measure/training/materials/ data-qualityportuguese/m_e_tool_series_indepth_interviews.pdf. Accessed 26 June 2013

Environmental Protection Act (2001) of 27 April 2001. Journal of Laws of 2008 no. 25 item 150

DG Enterprise and Industry (2010) Evaluation of SMEs' Access to Public Procurement Markets in The EU. http://ec.europa.eu/enterprise/ policies/sme/business-environment/files/smes_access_to_public procurement_final_report_2010_en.pdf. Accessed 26 June 2013

Kulczycka J, Kasprzak J, Kurczewski P, Lewandowska A, Lewicki R, Witczak A, Witczak J (2011) The Polish Centre for Life Cycle Assessment - the centre for life cycle assessment in Poland. Int $\mathrm{J}$ Life Cycle Assess 16(5):442-444

Regulation of the Council of Ministers on environmental fees dated 14 October (2008). Journal of Laws of 2008 no. 196 item 1217

Schischke K, Nissen NF, Sherry J, O'Rafferty, S, O’Connor F, Sitek J, Pamminger R, Wimmer W (2012) Life Cycle thinking in small and medium sized enterprises - Status quo and strategic needs in the electronics sector IN: Electronics Goes Green 2012+, Proceedings of the Joint International Conference and Exhibition September 9 - 12, 2012 Berlin, Germany pp 1-6

TNO report (2005) Making life cycle information and interpretative tools available, TNO report B\&O-A R 2005/326 http://ec.europa.eu/ environment/ipp/pdf/study_final_clean_report.pdf

Waste Act (2001) of 27 April 2001. Journal of Laws of 2001. no. 62. item 628 as amended

Water Act (2001) of 18 July 2001. Journal of Laws of 2005 no. 239 item. 2019 as amended 